\title{
Comensalidade.com - uma reflexão introdutória sobre as novas tecnologias e as práticas do comer junto
}

\section{Comensality.com - an introductory reflection on the new technologies and practices of eating together}

\section{Comensalidad.com - una reflexión introductoria sobre las nuevas tecnologías y las prácticas del comer junto}

\author{
Maria Henriqueta Gimenes-Minasse ${ }^{1}$ \\ Pedro Henrique Drudi ${ }^{2}$ \\ Andrea Ortolani Faltin ${ }^{3}$ \\ Mariana da Silva Lopes ${ }^{4}$
}

\begin{abstract}
Resumo: Este artigo trata das práticas comensalidade contemporâneas e tem como objetivo realizar uma reflexão introdutória sobre o uso de tecnologias associado às práticas do comer junto. Do ponto de visto metodológico esta discussão é realizada a partir de uma revisão bibliográfica e análise de exemplos contemporâneos. Foram identificadas várias iniciativas nas modalidades de blogs, websites e aplicativos que não apenas facilitam a aquisição de refeições e o acesso a restaurantes e similares, criando novos empreendimentos associados à área de alimentos e bebidas, mas também prometem aproximar profissionais e interessados em comida, bem como promover encontros entre desconhecidos ao redor da mesa. Constata-se que, seja para encontrar desconhecidos para dividir uma mesa, seja para compartilhar experiências de comensalidade ou ainda amenizar a solidão por meio da interação remota com outras pessoas, o uso de smartphones e similares durante as refeições já é uma constante na vida de milhares de pessoas e tem alterado as práticas de comer junto.
\end{abstract}

Palavras-chave: gestão em alimentos e bebidas; comensalidade; tecnologia; comportamento alimentar.

Abstract: This article deals with contemporary commensality practices and aims to conduct an introductory reflection on the use of technologies associated with the practices of eating together. From the methodological point of view this discussion is carried out from a bibliographical review and analysis of contemporary examples. Several initiatives have been identified in the form of blogs, websites and applications that not only facilitate the acquisition of meals and access to restaurants and the like, creating new enterprises associated with food and beverages, but also promise to bring professionals and interested in food, such as promoting encounters between strangers around the table. It is found that, whether to find strangers to share a table, to share experiences of commensality, or to ease loneliness through remote interaction with other people, the use of smartphones and the like during meals is already a constant in the life of thousands of people and has altered the practices of eating together.

Keywords: Management in food and beverages, commensality, technology, food behavior.

\footnotetext{
${ }^{1}$ Professor do Programa

${ }^{2}$ Mestre em Gestão em Alimentos e Bebidas pela Universidade Anhembi Morumbi. Professor da Graduação

Tecnológica em Gastronomia da Universidade Anhembi Morumbi. E-mail: phdrudi@ hotmail.com.

${ }^{3}$ Mestre em Hospitalidade pela Universidade Anhembi Morumbi. Professora da Graduação Tecnológica em

Gastronomia da Universidade Anhembi Morumbi. E-mail: andreafaltin@gmail.com.

${ }^{4}$ Doutoranda em Hospitalidade na Universidade Anhembi Morumbi. Professora da Graduação Tecnológica em

Gastronomia da Universidade Sagrado Coração. E-mail: ma.slopes@uol.com.br.
} 
Resumen: Este artículo trata de las prácticas contemporáneas de comensalidad y tiene como objetivo realizar una reflexión introductoria sobre el uso de tecnologías asociado a las prácticas del comer junto. Desde el punto de vista metodológico esta discusión se realiza a partir de una revisión bibliográfica y análisis de ejemplos contemporáneos. Se han identificado varias iniciativas en las modalidades de blogs, sitios web y aplicaciones que no sólo facilitan la adquisición de comidas y el acceso a restaurantes y similares, creando nuevos emprendimientos asociados al área de alimentos y bebidas, pero también prometen acercar a profesionales e interesados en comida, así como como promover encuentros entre desconocidos alrededor de la mesa. Se constata que, sea para encontrar desconocidos para dividir una mesa, sea para compartir experiencias de comensalidad o aún amenizar la soledad por medio de la interacción remota con otras personas, el uso de smartphones y similares durante las comidas ya es una constante en la vida de miles de personas y ha cambiado las prácticas de comer juntos.

Palavras-chave: gestión en alimentos y bebidas, comensalidad, tecnología, comportamiento alimentario.

\section{Introdução}

Em sua essência, a hospitalidade pode ser compreendida como um conjunto de práticas de acolhimento do outro, garantindo, por meio da hospedagem, da alimentação e do entretenimento o bem-estar de um convidado. Em relação à alimentação, Boutaud (2011) argumenta que compartilhar a mesa ou uma refeição consiste em uma das mais reconhecidas formas de hospitalidade, em qualquer recorte cronológico e em todas as culturas. Este compartilhamento, contudo, é um ato intricando, permeado por significados e simbolismos intrínsecos à complexidade do ato alimentar.

Como observa Alvarez (2002), a alimentação humana é um ato social e cultural onde a escolha e o consumo de alimentos colocam em jogo um conjunto de fatores de ordem ecológica, histórica, cultural, social e econômica ligados a uma rede de representações, simbolismos e rituais. Por consequência, como argumenta Barthes (2013), quando o homem moderno compra comida, a consome ou a serve, não está apenas manipulando um objeto, mas também constituindo uma informação e construindo significados, tornando as decisões alimentares uma forma de comunicação deste sujeito com o mundo. Isso se dá, porque, como ressaltam Bonin e Rolim (1991), os hábitos alimentares - que consistem nas decisões relacionadas à produção, escolha, preparo e consumo de alimentos - não são o espelho, mas a própria imagem de uma sociedade.

Analisando o contexto alimentar contemporâneo, verifica-se que a expansão da agroindústria dominada por empresas transnacionais fomenta o que Fischler (1995) denomina de alimentação hiper homogênea, resultado da homogeneização Inter territorial das dietas. Este processo é marcado pela produção de alimentos que tenham aceitação pela grande indústria, 
fazendo com que, muitas vezes, variedades de inúmeros ingredientes sejam desprezadas e entrem em risco de extinção (HERNANDEZ CONTRERAS; GRACIA ARNAIZ, 2011). Igualmente relevante é a popularização do sistema fast food de produção e consumo de alimentos a partir da década de 1960, que levou para o preparo de alimentos prontos para consumo uma lógica taylorista de produção de alimentos e o popularizou por meio de milhares de lanchonetes implantadas em todo o mundo (FISCHLER, 1998).

Como resultado deste processo de industrialização tem-se a transferência de uma parte substancial do esforço culinário coletivo da cozinha para a fábrica, transformando de forma radical o que comemos. Tem-se a criação e popularização do 'alimento serviço': um produto industrial como uma refeição congelada, cujo principal objetivo é economizar tempo no preparo, no serviço e no consumo de refeições (FISCHLER, 1995). Além do desenvolvimento de novos produtos alimentares, observa-se também o surgimento de inúmeros serviços voltados para facilitar o preparo e o consumo alimentar: pode-se comer comida de restaurantes em casa, comprar refeições congeladas por assinatura, reservar lugares em bares, restaurantes e similares, dentre outras possibilidades.

Verifica-se não apenas a ampliação da oferta de estabelecimentos, que assumem diferentes modelos e são desenvolvidos buscando agradar a diferentes demandas. Constata-se também a multiplicação de serviços intermediados por tecnologia, avanço este incentivado pela popularização da internet e de aparelhos como smartphones e similares. Como observa Lévy (2003), a internet cria novas maneiras de se informar, de se comunicar, de se divertir e de criar, transformando a forma com que os seres humanos interagem entre si e desenvolvendo uma sociedade pautada pela informaçãoo e comunicação. E as práticas alimentares não escapam deste conjunto de mudanças, gerando, segundo Rousseau (2012) algumas mudanças. Dentre elas, talvez a mais significativa seja o justamente o aumento da exposição à comida, que termina não apenas por mudar a forma com que pensamos sobre comida, mas também o quanto pensamos sobre ela.

Por consequência, esta nova visibilidade e a criação de novos negócios consolida uma fetichização da comida, fazendo com que ela, assim como outros objetos de consumo, seja revestida de um aspecto lúdico (DEBORD, 1997). Assim, fotos e comentários sobre comida e bebida ganham presença massiva em redes sociais (na rede social Instagram , por exemplo, a 
hashtag \#food revela centenas de milhões de fotos) e passam a influenciar o comportamento de milhares de comensais em todo o globo (Hall, 2016; Hosie, 2017).

Desta forma, redes sociais, blogs e aplicativos se tornam não apenas fonte de informações para potenciais clientes, mas também canais de contato com outros comensais e também com os estabelecimentos, consolidando-se como um espaço muito utilizado para divulgar suas impressões e preferências alimentares. Essas novas práticas alteram não apenas a forma de escolha de um bar ou similar, mas também a forma com que as pessoas se relacionam com e por meio da comida e da bebida.

A problemática de pesquisa que deu origem a este artigo consiste em tentar perceber de que forma as novas tecnologias - e os produtos e serviços a ela relacionados - estão modificando as práticas de comensalidade na contemporaneidade. Tendo em vista tratar-se de um tema complexo que demanda esforços metodológicos de diversas ordens, este artigo apresenta os resultados iniciais de desenvolvimento de tal problemática, e tem como objetivo geral realizar uma reflexão introdutória sobre o uso de tecnologias associado às práticas de comensalidade na contemporaneidade.

\section{Apontamentos teóricos sobre as práticas de comensalidade}

Etimologicamente, a palavra comensalidade deriva do latim "comensale" - (com: junto, mensa: mesa) e significa o ato de comer junto, de partilhar do mesmo momento e do mesmo local das refeições (Poulain, 2013). As práticas de comensalidade relacionam-se não apenas à ingestão de alimentos, mas também aos modos de comer, e exprimem hábitos culturais, atos simbólicos, regras de organização social e valores, além do compartilhamento de experiências (Fischler, 2011).

Esta concepção, apesar de sintética, aglutina múltiplos significados. A comensalidade implica no exercício de sociabilidade, que é descrita por Baechler (1995) como a capacidade humana de estabelecer laços, conectando, mesmo que momentaneamente, os indivíduos envolvidos. Como observam Lashley, Morrinson e Randall (2005) a comensalidade é dotada de funções sociais e simbólicas que a tornam uma importante estratégia para a criação e o fortalecimento de laços entre pessoas. Para Tuoumainem (2014) a prática de comer junto significa, na maioria dos contextos culturais, uma expressão de unidade social. 
Ser convidado para uma refeição compartilhada é um símbolo de aceitação e pressupõe a existência de uma proximidade (social e/ou afetiva) entre as pessoas ou pelo menos da promessa desta proximidade. Para Beardsworth e Kiel (1997) o ato de comer reside no ponto de interseção de toda uma série de intricados processos fisiológicos, ecológicos, econômicos, políticos, sociais e culturais, fazendo com que o ato de partilhar uma refeição permita unir simbolicamente os comensais.

Fischler (2011) reforça que a comensalidade é muito mais ampla do que simplesmente comer com outras pessoas, já que compartilhar uma refeição pressupõem algum grau de dependência entre os comensais ou algum grau de comprometimento e envolvimento recíproco. Por consequência, a comensalidade pode manifestar igualdade ou hierarquia. Enfatizando que a associação entre comensalidade e sociabilidade - "if eating a food makes one become more like that food, then those sharing the same food become more like each other" -, o autor observa que a comensalidade pode, ao ser capaz de estabelecer intimidade, preservar e revitalizar laços de parentesco, bem como criar e reforçar um parentesco 'artificial' a partir de laços fraternais entre amigos (FISCHLER, 2011, p.534). Tem-se, então, que a comensalidade não apenas age como uma forma de conexão com o outro, mas também constitui um meio de aprender sobre o outro e inserir-se - bem como manter-se - simbolicamente vinculado a um determinado grupo. De forma oposta, como observam Grassi (2011) e Fischler (2011), ser excluído da mesa é ser excluído de um grupo.

Justamente por conta dos diferentes vieses envolvidos na prática da comensalidade, Simmel (1998) defende que a experiência de compartilhar uma refeição é uma parte importante do processo de socialização, permitindo que um indivíduo não apenas aprenda, mas também reforce de forma continuada normas sociais que incluem decisões sobre o que, como, quando e com quem realizar suas refeições. Em um raciocínio semelhante, Carneiro (2005, p.71), observa: “Comer não é um ato solitário ou autônomo do ser humano, ao contrário, é a origem da socialização, pois, nas formas coletivas de se obter a comida, a espécie humana desenvolveu utensílios culturais diversos, talvez até mesmo a própria linguagem”, servindo para organizar as regras de identidade, de hierarquia social, tecer redes de relações e também impor limites e fronteiras sociais, políticas e religiosas.

Ao se refletir sobre comensalidade, é preciso considerar, portanto, a dimensão do que Boutaud (2011) denomina 'comer simbólico'. A partir de uma perspectiva boudieusiana de 
gosto 5 tem-se que o gosto alimentar é uma fusão do gosto biológico (fruto das operações físicoquímicas desempenhadas pelos órgãos de sentido para criar o paladar) com o gosto social, fazendo com que as escolhas individuais relacionadas aos alimentos se inscrevam em um contexto mais amplo, de caráter sociocultural. Nesta perspectiva é relevante recuperar a partir da noção de consumo simbólico trabalhada por Douglas e Isherwood (2006) e Baudrillard (2009) que parte do pressuposto de que os bens não são consumidos apenas por sua utilidade, mas também pelos valores sociais que lhe são atribuídos e pelas relações que podem ser estabelecidas com e por meio destes objetos. Nesta perspectiva, um alimento não é consumido apenas por suas características nutricionais, mas também por aquilo que ele representa e pelas relações que podem ser estabelecidas a partir dele. Desta forma, come-se para demarcar o pertencimento a um determinado grupo ou religião, para demarcar status ou exprimir uma ideologia (GIMENES-MINASSE, 2013).

O contexto cultural de um grupo, como já observado, termina por estruturar as práticas alimentares de um grupo. Como observa Barbosa (2007, p. 93): “toda sociedade estabelece normas e momentos específicos, em que determinados tipos de comida são ingeridos preferencialmente a outros, em uma determinada sequência, dentro de uma certa lógica de ingestão e de combinação dos alimentos entre si. Esses momentos são denominados refeições". Assim, os valores atribuídos socialmente a determinados alimentos, práticas alimentares, contextos e lugares de degustação também merecem atenção. Para Woortmann (1985) o caráter simbólico-ritual do comer se expressa claramente no hábito de convidar pessoas para jantar em nossa casa, no "jantar fora" em determinadas ocasiões ou no "almoço de domingo". Segundo o autor, nessas e em outras situações semelhantes há mais em jogo que necessidades nutricionais: "Não convidamos pessoas para jantar em nossa casa para alimentá-las, enquanto corpos biológicos, mas para alimentar e reproduzir relações sociais, isto é, para reproduzir o corpo social, o que supõe que sejamos em troca convidados a comer na casa do nosso convidado. O que está em jogo é o princípio da reciprocidade e da comensalidade (WOORTMANN, 1985, p.3).

\footnotetext{
${ }^{5}$ Para BOURDIEU (1983) para quem o gosto caracteriza uma propensão e uma aptidão à apropriação material e simbólica de uma determinada categoria de objetos ou práticas classificadas e classificadoras, constituindo a fórmula generativa de um estilo de vida.
} 
Baseando-se em suas pesquisas realizadas na década de 1980, Woortmann (1985) atesta que no contexto cultural brasileiro uma refeição é considerada um ato social, e deve ser realizada em grupo para ser percebida como tal. E que diferentes significados são produzidos para diferentes tipos de atos alimentares, tais como comer cotidianamente ou comer em eventos especiais, comer em casa ou comer fora dela. Já Barbosa (2007), baseando-se nos dados de uma pesquisa realizada em 2006 sobre os hábitos alimentares dos brasileiros, identifica diferenças entre os comportamentos adotados durante e no final de semana. Estas diferenças dizem respeito à composição do cardápio, ao número e horário das refeições, mas também aos significados atribuídos a elas. O café da manhã, apesar de ser a refeição mais realizada em casa, não é considerado uma refeição familiar (no sentido de reunir a família em torno da mesa). "No cotidiano ele é ingerido de forma bastante individualizada, devido às múltiplas atividades dos membros da família ou do grupo doméstico" (BARBOSA, 2007, p. 102).

O almoço ainda é para muitos uma refeição familiar, mas o jantar é indicado pela grande maioria dos respondentes como a refeição que mais reúne a família, aquela em que as pessoas têm mais tempo e podem comer com calma. Mas a autora destaca uma tendência à informalidade à mesa, tendo em vista que "as pessoas parecem comer de forma volante, principalmente no jantar, ou seja, fazem o prato e vão comer em frente à TV, na sala ou no quarto" (BARBOSA, 2007, p.96). O hábito de fazer as refeições com a televisão ligada é destacado, sendo que o aparelho às vezes funciona como um "pano de fundo" e às vezes orienta e motiva as conversas. Contudo, os depoimentos coletados reafirmam, tanto para homens quanto para mulheres, a importância da reunião familiar no jantar, percebido como o momento da família "[...] se encontrar e de estar junta, dos pais saberem sobre os filhos e dos laços familiares e de comensalidade serem reafirmados. Nesse contexto, a TV idealmente, para muitos, não deveria estar lá, mas todos parecem aceitá-la como uma presença que não é possível dispensar" (BARBOSA, 2007, p.105).

Outro aspecto que merece destaque nos dados relatados por Barbosa (2007) diz respeito à percepção de que a comida no Brasil é uma fonte de prazer, de união familiar e de comensalidade. O ápice desta possibilidade do encontro, ao que tudo indica, continua sendo o final de semana, que age muitas vezes como contraponto dos hábitos exibidos durante a semana. Muitas das contribuições de Barbosa (2007) também ficam evidentes na pesquisa realizada por Carvalho et al. (2017) sobre as mudanças percebidas na comensalidade de 
famílias paulistanas entre 1950 e 2000. Os autores observam, a partir da análise de entrevistas realizadas com representantes de três gerações de famílias paulistanas, que a comensalidade cotidiana foi alterada, não apenas pela entrada da mulher no mercado de trabalho, mas também pela busca por praticidade e pela incorporação de equipamentos domésticos (que alteram a forma de preparar e degustar alimentos) e de novos serviços de alimentação que surgem para atender às novas necessidades (como buffets para festa e serviços de delivery).

Os autores verificam ainda a ocorrência de um movimento de transição, que retira a alimentação do domínio quase que exclusivamente familiar e a estabelece como um elemento central de um mercado em expansão; bem como a forma com que tais inovações são 'negociadas' pelos mais velhos, que tentam manter algumas tradições - por exemplo, já que não é possível mais reunir a família ao redor da mesa durante a semana, a prática da comensalidade restringe-se ao final de semana, mas torna o almoço familiar de domingo um compromisso praticamente inegociável. Ainda, o uso da televisão de forma concomitante às refeições também é observado, verificando-se outra inclusão tecnológica nas gerações mais jovens: passa-se a identificar o hábito de alimentar-se também em frente ao computador (CARVALHOo et al., 2017). Em nenhuma das pesquisas (uma finalizada em 2000 e outra em 2006), contudo, é mencionada a presença de smartphones.

Como observam Sobal et al. (2003), na atualidade, as práticas de alimentação e de comensalidade podem ocorrer em diferentes espaços e ocasiões, tais como no ambiente doméstico (com destaque para o papel da família nuclear), no refeitório de empresas, em cafeterias e em ocasiões festivas. Assim, ao poder ser exercitada tanto no âmbito público ou no privado, na esfera domiciliar ou comercial, a comensalidade pode ser encarada de diversas formas. E, por pertencer ao domínio das práticas culturais, a comensalidade também se mostra muito responsiva às mudanças socioeconômicas e culturais que atingem determinados grupos sociais.

Para Cho et al. (2015) comer é um evento psicológico e social, e estudos empíricos tem demostrado como a presença ou ausência do outro durante uma refeição tem um impacto significativo na experiência do comer. Por exemplo, a associação entre prazer e o comer acompanhado, em contraponto ao stress do comer sozinho, ou ainda a percepção de que comer sozinho não constitui efetivamente uma refeição. Contudo, como observam os autores, as práticas de comensalidade estão sendo enfraquecidas nos grandes centros urbanos por uma 
série de motivos, inclusive pelo fato de que atualmente há um maior contingente de pessoas morando sozinhas.

Neste contexto, tem-se observado que o aumento do consumo individualizado de refeições e o consequente declínio das refeições compartilhadas tem suscitado a atenção de pesquisadores ligados a diferentes áreas do conhecimento. Pode-se mencionar, dentre outros, trabalhos realizados no exterior como os de Traphagan e Brown (2002), que trata da comensalidade inter geracional em restaurantes de fast food no Japão; de Grevet et al. (2012), que estudaram o uso de tecnologias de interação para amenizar os efeitos das refeições solitárias em universitários; e o de Danesi (2014), sobre as práticas de comensalidade de jovens franceses, alemães e espanhóis na atualidade. Da mesma forma, destaca-se a já mencionada contribuição de Fischler (2011) sobre questões relacionadas à comensalidade contemporânea.

No Brasil, contudo, a questão da comensalidade contemporânea tem sido investigada principalmente do pronto de vista nutricional, com vários estudos procurando observar seu papel regulador em relação aos hábitos alimentares, como é o caso da pesquisa de Lopes (2011), que estuda a comensalidade entre diabéticos no contexto do ambiente familiar; ou do ponto de vista antropológico, abordando práticas de comensalidade em sociedades tradicionais, como é o exemplo da pesquisa de Costa (2013), que analisa as práticas de comensalidade no contexto das relações de parentesco dos índios Kanamari na Amazônia Ocidental. Há ainda exemplos relacionados ao estudo da produção científica sobre comensalidade (Soares e Camargo, 2015), à análise da comensalidade e hospitalidade estudadas a partir de restaurantes, como é o exemplo de De Boer e Rejowski (2016), e também ao estudo da comensalidade em celebrações religiosas, como a publicação de Gastal e Martins (2018). De forma específica, considerando a aderência a esta discussão, destacam-se os artigos de Barbosa (2007) e Carvalho et. al. (2017), incorporados nesta discussão teórica.

\section{Metodologia}

Tendo em vista a problemática proposta e o objetivo geral selecionado para este artigo, verifica-se que os resultados aqui apresentados são fruto de uma etapa exploratória, que busca maior compreensão do objeto coletando e articulando informações que poderão fomentar a construção de hipóteses que serão testadas nas etapas seguintes da pesquisa (Dencker, 1999). Neste sentido este artigo é resultado de uma pesquisa bibliográfica, baseada em livros e artigos 
científicos, centrada nos temas comensalidade e consumo alimentar contemporâneo, que foi utilizada para analisar exemplos contemporâneos de usos da tecnologia associados a práticas de comer junto. A partir dos termos de busca comensalidade, commensality, consumo alimentar e food consumption foram realizados levantamentos nas bases de dados Scielo, Scopus e Banco de Periódicos da CAPES e, a partir dos resultados encontrados, foram selecionados os artigos que possuíam aderência à esta proposta de pesquisa.

\section{Análise dos resultados}

Como já observado, os avanços tecnológicos de diversas ordens ocorridos nas últimas décadas transformaram os hábitos cotidianos de inúmeros usuários em todo o mundo. $\mathrm{E}$ o campo da alimentação não passou incólume. Percebendo a importância deste novo canal de informação, muitos bares, restaurantes e similares criaram websites com o objetivo de divulgar e oferecer informações para seus clientes reais e potenciais. Não obstante, surgiram uma série de novos serviços - de aplicativos e redes sociais - que prometem novas formas de aquisição de refeições e interações entre comensais. O quadro 1 ilustra este ponto de vista, apresentando alguns dos muitos exemplos identificados no levantamento realizado:

\begin{tabular}{|l|l|l|}
\hline & Modalidade & Exemplos \\
\hline 1 & Blogs e websites específicos sobre restaurantes & Gastrolandia, Guia Michelin, Zagat, FoodStar \\
\hline 2 & Aplicativos de serviços de delivery & Hello Food, Ifood, Spoon Rocket, Uber Eats \\
\hline 3 & $\begin{array}{l}\text { Aplicativos para reserva em restaurantes e } \\
\text { similares }\end{array}$ & $\begin{array}{l}\text { OpenTable, Restorando, Table4, The Fork Restaurant, } \\
\text { Sixplus }\end{array}$ \\
\hline 4 & $\begin{array}{l}\text { Aplicativos para compartilhamento de } \\
\text { refeições }\end{array}$ & $\begin{array}{l}\text { Apptite, Crushing Table, Dineer, Eatwith, HomeyCook, } \\
\text { Kitchennd, Mealsharing,VizEat }\end{array}$ \\
\hline 5 & $\begin{array}{l}\text { Aplicativos para encontros amorosos em } \\
\text { restaurantes e similares }\end{array}$ & Lobstr, Napkin Social \\
\hline 6 & Redes sociais específicas sobre comida & Chefstalk, Feastly, Foodily, Tastemade \\
\hline
\end{tabular}

Quadro 1 - Exemplos de aplicativos e redes sociais associados à comida

Fonte: os autores (2017)

Dentre os exemplos elencados, os guias informativos e os serviços de delivery são os mais usuais, sendo estes pré-existentes em outras plataformas. Transferidos para a esfera digital, contudo, ganham um novo apelo e uma nova dimensão de acesso. Há inúmeros blogs e websites dedicados a caracterizar e emitir opiniões sobre bares, restaurantes e similares. Alguns deles são mantidos por críticos gastronômicos que migraram de outras mídias (principalmente a impressa); por desconhecidos que se interessam por comida e bebida; ou são versões digitais de 
guias internacionalmente famosos, como o Guia Michelin (https://www.viamichelin.pt/web/Restaurantes/Restaurantes-Brasil) e $\quad$ o Zagat (https://www.zagat.com/ ). Há ainda exemplos como o FoodStar (https://foodstar.com.br/foodstar-home), onde os próprios usuários cadastrados opinam sobre os estabelecimentos frequentados e contribuem para a constituição de um ranking próprio.

A oferta de aplicativos dedicados ao serviço de delivery de refeições também é vasta, sendo a grande tônica desta oferta a promessa de entrega de comidas diversas, provenientes de diferentes estabelecimentos, em tempo ágil (muitos divulgam que o intervalo entre o início do pedido e o recebimento da comida é de no máximo 35 minutos) e preservando o sabor, a temperatura e a aparência dos alimentos. Destaca-se, dentre os exemplos mencionados, o aplicativo Ifood (https://www.ifood.com.br/ ).

Criado em 2013, o iFood está presente em várias cidades do Brasil e da América Latina e tornou-se nacionalmente conhecido depois de veicular propagandas em canais de televisão. Mas, ao contrário de seus concorrentes, este aplicativo não se apresenta apenas como uma opção para quem busca um serviço de entrega ágil de uma comida saborosa. A página de abertura do aplicativo exibe a mensagem "Somos inspirados pelas relações criadas ao redor da mesa" seguida pela frase "Nós levamos comida para alimentar momentos importantes na vida das pessoas" (IFOOD, 2017). Desta forma, estabelece-se um apelo diretamente relacionado à comensalidade e ao prazer de dividir uma refeição, bem como busca-se fugir do estereótipo de que o serviço de delivery deve ser utilizado apenas em situações 'emergências', quando não se possui companhia para ir jantar ou não se tem tempo hábil para almoçar fora do escritório.

É preciso mencionar ainda os aplicativos e websites que permitem que sejam feitas reservas em bares, restaurantes e similares rapidamente. Alguns websites de guias, como o Zagat e Foodstar, oferecem também esta facilidade. A diferença entre os aplicativos exclusivos para este fim consiste na oferta de outras facilidades, como o acúmulo de benefícios mediante o uso regular do dispositivo (como o Restorando - https://restorando.com.br/ ), descontos ou promoções para reservas feitas pelo aplicativo (como o The Fork Restaurant https://theforkrestaurant.com.br ) ou ainda a possibilidade de escolher a mesa em que se deseja sentar (como o Table4 - http://www.table4.com.br/ , website especializado em reservas em restaurantes de alto padrão). 
Estes exemplos remetem à possibilidade do exercício da comensalidade, na medida em que prometem agilizar o acesso a restaurantes e similares - ou à comida propriamente dita, mas não determinam que ela aconteça (pode-se reservar apenas um lugar ou degustar a comida entregue em casa sozinho). Há, contudo, alguns exemplos que oferecem diretamente novas possibilidades de vivência da comensalidade: websites e aplicativos destinados ao compartilhamento de refeições e até mesmo aqueles cujo objetivo é promover encontros amorosos em restaurantes e similares.

Iniciativas como o Crushing Table (http://crushingtable.com.br/) , o Eatwith (https://www.eatwith.com/ ) e o VizEat (https://www.vizeat.com/) buscam promover o encontro encontro entre pessoas com pontos em comum tendo como foco central uma experiência gastronômica. O Crushing Table é um aplicativo criado por empreendedores brasileiros em 2015, atualmente tem abrangência internacional e pode ser acessado em português, inglês e espanhol. Tem como lema 'Vamos dividir uma mesa'. O aplicativo permite o cadastro de usuários/pessoas físicas, para quem promete a possibilidade de conhecer pessoas e fazer novos amigos, ou desenvolver contatos de caráter profissional ou amoroso; e de empreendimentos/pessoas jurídicas, para quem se estabelece como uma alternativa para divulgar o estabelecimento e aumentar a lucratividade a partir do aumento da taxa de ocupação da casa (CRUSHING TABLE, 2017).

O usuário tem a possibilidade de se cadastrar usando seu e-mail ou seu perfil no Facebook (https://pt-br.facebook.com/) e pode abrir uma mesa (fazer uma reserva em um restaurante e disponibilizá-la) para até quatro pessoas, ou ainda se candidatar para uma mesa aberta por outro usuário. Ao abrir a sua reserva, o usuário deve indicar se pretende fazer amigos, paquerar ou realizar networking, podendo definir, inclusive, o perfil de companhia que deseja (masculina, feminina, LGBT ou ainda não especificar nenhuma preferência). É possível dividir uma mesa em várias cidades do mundo e ainda acertar detalhes com os desconhecidos que se tornarão seus comensais por meio da troca de mensagens, sem que haja o pagamento de qualquer taxa (NERI, 2015; POLLO, 2016; CRUSHING TABLE, 2017).

Não há nenhum custo para o usuário, e o cadastramento de empreendimentos se dá por meio do pagamento de uma mensalidade. Por meio do aplicativo o estabelecimento divulga quantas mesas estão disponíveis para compartilhamento e em quais horários e datas, e ainda se há alguma promoção vinculada, como drinks cortesia, brindes ou pratos a preços promocionais 
(CRUSHING TABLE, 2017). Em 2016 o Crushing Table já contava com 3,9 mil usuários cadastrados e segundo reportagens sobre o aplicativo, um dos seus maiores apelos junto aos usuários não é apenas a possibilidade de 'não comer sozinho', mas principalmente conhecer pessoas diferentes, com interesses diferentes, extrapolando o círculo de amizades que o indivíduo já possui (NERI, 2015; POLLO, 2016).

O EatWith é uma plataforma digital criada em Israel em 2013. Tem como lemas 'the future of dining is here' e 'bringing people together, one meal at time'. Atualmente tem mais de 650 anfitriões cadastrados em mais de 200 cidades no mundo. O aplicativo permite que o usuário escolha dentre as inúmeras experiências gastronômicas (almoços, jantares, chás e até mesmo tours gastronômicos) oferecidas pelos anfitriões em dias, horários e locais prédefinidos. E estas experiências podem ser compartilhadas com desconhecidos ou agendadas para eventos privados, como festas de aniversário ou reuniões de empresas (SALLES, 2013).

Um aspecto interessante é que não é preciso ser um cozinheiro profissional para cadastrar-se como anfitrião, e muitas das experiências oferecidas têm como local a própria residência de quem irá cozinhar. O momento de escolha da experiência permite ainda selecionar a cidade você também pode selecionar o tipo de culinária, a média de preço e as características do espaço onde ela acontecerá (se é uma casa, um apartamento, uma cobertura, no centro da cidade, ao ar livre ou em um lugar com uma vista de destaque). As experiências gastronômicas são pagas, e os valores são informados juntamente com o descritivo de cada atividade, e os anfitriões só são credenciados depois que seus serviços são testados por representantes da empresa. No Brasil o EatWith está presente em Brasília, Rio de Janeiro e São Paulo (SALLES, 2013; EATWITH, 2017).

O VizEat é destinado a turistas que desejam ter experiências gastronômicas mais autênticas nos locais que visitam. O aplicativo conta atualmente como 20.000 hosts (pessoas que oferecem tais experiências) em 110 cidades do mundo, e possuem aproximadamente 150.000 usuários cadastrados. O objetivo é permitir que os viajantes conheçam novas pessoas e façam novos amigos enquanto usufruem de uma experiência gastronômica memorável (que pode incluir um almoço ou jantar na casa de um host ou aulas de culinária, experiências sempre compartilhadas com outros usuários). Segundo a página do aplicativo, "VizEat allows travelers to make meaningful connections with locals as they discover the world and eat local. As the world transitions to online connections, VizEat aims to maintain the human 
element many travelers find missing and believe the strongest connections take place sharing a meal" (VIZEAT, 2017).

Há ainda outros aplicativos que possuem apelos específicos, como aqueles que prometem a possibilidade de compartilhar boas refeições caseiras na casa dos anfitriões, também mediante pagamento: a Kitchennd (http://www.kitchennd.com.br/), uma plataforma digital criada por empreendedores brasileiros que une quem gosta de uma boa refeição caseira com quem gosta de cozinhar, e a Mealsharing (https://www.mealsharing.com/) uma plataforma digital que também promete unir comensais e cozinheiros em refeições caseiras pagas.

O aplicativo Lobstr (https://www.getlobstr.com/?hl=pt), por sua vez, também busca promover o encontro entre desconhecidos em restaurantes e similares, mas a tônica é a de um relacionamento amoroso. Seu lema é "Lobstr é um aplicativo de relacionamento diferente de tudo que você já experimentou. Queremos tirar você dos bate-papos virtuais sem fim, e colocar você frente a frente com aquela pessoa especial. Sem pressão, na hora do almoço, em seu restaurante favorito" (LOBSTR, 2017). Lançado em junho de 2017, trata-se de um aplicativo de paquera desenhado para a cidade de São Paulo e que tem como público alvo paulistanos entre 35 a 45 anos. O aplicativo está disponível gratuitamente e, ao se cadastrar, o usuário pode inserir até três fotos em seu perfil e deve escolher, em uma lista do website Yelp (uma rede social baseada na avaliação de negócios locais), dois dos seus restaurantes preferidos. Há duas maneiras de se conseguir um encontro: anonimamente (como no Tinder, marca-se o interesse em uma pessoa sem que ela saiba, se o interesse for mútuo ambos recebem uma notificação e o próprio aplicativo sorteia um restaurante entre os existentes nos perfis do dois, que passam a trocar mensagens para agendar o almoço) ou de forma não anônima, quando um usuário decide o local do encontro a partir dos restaurantes previamente listados como preferidos e, caso a outra pessoa aceite, é possível trocar mensagens (MENEZES, 2017).

$\mathrm{O}$

Napkin

Social

(https://play.google.com/store/apps/details?id=com.social.napkin\&hl=pt_BR) também é um aplicativo de relacionamentos, que promete aproximar pessoas otimizando a antiga prática de trocar mensagens em guardanapos em bares, restaurantes e similares. O lema é "Seu guardanapo virtual de mensagens". O aplicativo permite que pessoas que estejam fisicamente no mesmo lugar (evento ou localidade) iniciem uma conversa. O aplicativo promete aproximar pessoas em ambientes em que elas costumam frequentar e também pode auxiliar os usuários na 
tomada de decisão sobre qual evento ou localidade frequentar, já que disponibiliza informações relacionadas à quantidade de pessoas on line e disponíveis em cada lugar, de acordo com as preferências de orientação sexual e faixa etária do usuário. Desta forma, o Napkin também incentiva pessoas a irem a determinados lugares, beneficiando também os estabelecimentos locais, que podem oferecer benefícios aos seus usuários (NAPKIN SOCIAL, 2017).

Embora o Facebook esteja repleto de comunidades voltadas para a gastronomia e o Instagran (https://www.instagram.com/?hl=pt-br) possua inúmeros perfis que se dedicam basicamente à postagem de fotos de comida e bebida, há ainda redes sociais específicas para profissionais e apreciadores de gastronomia. O Feastly (https://eatfeastly.com/ ) é uma plataforma que promete unir chefs, cozinheiros amadores e comensais ao redor do mundo, proposta semelhante à da plataforma Chefstalk (http://chefstalk.com/ ), uma rede social exclusiva para chefs e entusiastas de comida. Nestas comunidades - assim como acontece com o Facebook e o Instagran - é comum que os usuários façam upload de fotos e vídeos, e até mesmo transmissões ao vivo - enquanto cozinham e/ou fazem suas refeições. Estas postagens muitas vezes geram interações imediatas com outros usuários, permitindo que, mesmo sentado de forma isolada em um restaurante, o indivíduo mantenha uma conversação digital com seus amigos virtuais.

Tomando por base estes exemplos, fica evidente que a internet, por meio de redes sociais e plataformas digitais, cria um conjunto de espaços sociais - mesmo que virtuais - para os quais convergem comensais, chefs e empresários, construindo não apenas novas formas de se informar, de se comunicar e de se divertir como já apontado por LÉVY (2003), mas também novas formas de empreendedorismo, de consumo e de articulação entre pessoas de interesses semelhantes.

Em tempos de alteração de práticas alimentares, a comensalidade persiste. Se não já não há mais tempo disponível ou habilidade culinária necessária para se cozinhar em cada, frequenta-se bares, restaurantes e similares, ou simplesmente reúne-se amigos e familiares em casa e pede-se comida por um smartphone.

Observa-se que a forma tradicional de comensalidade envolve a presença física dos comensais, que se reúnem de forma articulada a partir da figura de um anfitrião. O primeiro ponto que merece destaque é a questão da proximidade física. Em um ambiente comercial, verifica-se a convivência de inúmeras pessoas durante o momento da refeição, mas esta muitas 
vezes se limita ao compartilhamento do espaço - e não da refeição, tendo em vista que esta possibilidade fica restrita àqueles que compartilham efetivamente da mesma mesa. É possível verificar, em restaurantes, lanchonetes e similares pessoas que, apesar de realizarem sua refeição com uma proximidade física bastante razoável, estejam na verdade, comendo sozinhas.

Com a popularização de tecnologias como smartphones e internet wireless, a proximidade física passa a ser relativizada em vários momentos. Pode-se conversar em tempo real - e com direito a imagens - com qualquer pessoa que tenha os mesmos aparatos que você. Da mesma forma, a popularização de redes sociais criou uma série de possibilidades de interação: pode-se marcar sua localização, postar fotos, fazer vídeos e enviar áudios para amigos e desconhecidos. As novas formas de interação humana, intermediadas pela tecnologia, se tornaram tão banais que também interferem e modificam os momentos das refeições (ROUSSEAU, 2012).

Como discutido anteriormente a partir de FISCHLER (2011), a comensalidade é capaz de produzir laços, reforçando relações de parentesco sanguíneo e até mesmo 'artificial', aquele estabelecido a partir da fraternidade entre amigos. A comensalidade, ressalta este autor, pressupõe ou estabelece intimidade. No caso dos aplicativos que prometem o encontro de desconhecidos ao redor da mesa, a intimidade anterior não existe e a sociabilidade ao redor da mesa não pretende reforçar laços ou demarcar o pertencimento a um determinado grupo, assumindo exclusivamente a função de estabelecer novos laços, mesmo que fugazes. A duração de uma refeição parece ser suficiente para decidir se há o interesse em manter contato ou não com as pessoas recém-conhecidas.

Por outro lado, também é possível que a tecnologia iniba momentos de comensalidade. Como ressaltam MOSER et al (2016), na medida em que o uso contínuo de celulares cresce durante as refeições, inúmeras tensões se apresentam, já que o uso destes aparelhos tende a diminuir o nível e a qualidade das interações durante as refeições. MISRA et ali (2014) ao estudarem a relação entre a presença de smartphones e a qualidade da interação social entre pessoas observaram que as conversações que ocorrem longe da presença destes aparelhos tendem a ser mais intensas do que na presença deles, e que o não uso do equipamento também permite o aumento do nível de empatia demonstrado entre os sujeitos.

De fato, imagens de um grupo de amigos ou familiares sentados ao redor de uma mesa, mas dispersos individualmente nas telas de seus celulares tem se tornado comuns em 
restaurantes do todo o mundo. Como contraproposta, além de brincadeiras como "todos os celulares na mesa, que pegar o seu primeiro paga uma rodada de bebidas ou a conta inteira", alguns estabelecimentos têm tentado criar mecanismos para promover a volta da conversa à mesa. O bar Salve Jorge, na Vila Madalena, em São Paulo, criou em 2013 o 'copo offline', um copo de chopp que só permanece em pé com o celular (no padrão smartphone) apoiado em sua base. O design do copo foi pensado de forma não apenas a depender do apoio do celular, mas também de forma a não prejudicar o aparelho, tendo em vista a espessura do vidro que impede que a bebida sue e umedeça o aparelho (VEJA, 2013).

A ideia foi motivada pelo fato de que "Bares não foram criados somente para pessoas que querem ingerir bebidas alcoólicas - e sim para os que desejam relaxar e interagir com amigos e conhecidos. Mas, em tempos de redes sociais e relacionamentos virtuais, o telefone celular tem se tornado o principal companheiro dos clientes" (VEJA, 2013, [s.d]) e pela intenção de fazer com que a conversa 'olho no olho' volte à cena e que o cliente possa aproveitar a companhia das pessoas que já estão com ele no estabelecimento.

No mesmo ano a cervejaria gaúcha Polar lançou um porta-garrafas de plástico com um dispositivo para anular o sinal de celulares por até um metro e meio que é acionado com a inserção da garrafa (CAMPI, 2013). O dispositivo, denominado 'Anulador de Celular Polar", cujo objetivo é que o comensal possa se desconectar do mundo em prol das boas companhias, um bom papo e uma cerveja gelada (EXAME, 2013).

\section{Conclusão}

A comensalidade parece ser, mais do que uma dimensão da hospitalidade, uma prática inerente do comportamento humano, estando presente - com regras próprias e características específicas - em todas as culturas do globo. E mesmo em tempos de alteração dos padrões alimentares, a valorização da comensalidade continua, mesmo que estejam ocorrendo reconfigurações do hábito de partilhar refeições na tentativa de garantir (mesmo que de forma suprimida) tais momentos.

Compartilham-se refeições em casa, na rua, em estabelecimentos comerciais convencionais ou na própria casa de chefs, mediante pagamento. Divide-se a mesa com familiares, amigos, amigos de amigos e até mesmo - e intencionalmente - com completos estranhos. 
As refeições individuais predominam em alguns contextos, mas as práticas de comensalidade continuam a ser percebidas como fundamentais para a criação e fortalecimento de laços entre pessoas, uma prática capaz de vincular um indivíduo a um grupo. Contudo, perspectivas relacionadas à necessidade da presença física e da existência de uma relação prévia (mesmo que superficial) entre os comensais parecem estar sendo relativizadas. Neste ponto, a tecnologia ganha um destaque que não era vislumbrando inicialmente. Se a televisão aparece com destaque em algumas pesquisas, já estando completamente assimilada às práticas de alimentação em muitas residências, são as tecnologias móveis que estão moldando definitivamente as novas formas de se compartilhar uma refeição.

Seja para encontrar desconhecidos para dividir uma mesa, seja para compartilhar experiências de comensalidade ou ainda amenizar a solidão por meio da da interação remota com outras pessoas, o uso de smartphones e similares durante as refeições já é uma constante na vida de milhares de pessoas. Este uso tem sido tão intenso que já são levantadas dúvidas sobre seu impacto na qualidade das interações humanas e no próprio exercício da comensalidade. Os exemplos aqui apresentados convidam para uma reflexão preliminar que ainda deve ser desenvolvida de forma pormenorizada. Espera-se que as próximas etapas desta pesquisa possibilitem uma melhor compreensão sobre as relações existentes entre o uso de tecnologias e as práticas de comer junto.

\section{REFERÊNCIAS}

ALVAREZ, M. La cocina como patrimônio (in)tangible. Primeras jornadas de patrimonio gastronômico. CPPHC-CABA: Buenos Aires, 2002, p.11-26.

BAUDRILLARD, J. O sistema de objetos. 5.e.d São Paulo: Perspectiva, 2015.

BAECHLER, J.. Grupos e sociabilidade. Boudon, Raymond. (org). Tratado de sociologia. Rio de Janeiro: Jorge Zahar, 1995.

BARBOSA, L. Feijão com arroz e arroz com feijão. O Brasil no prato dos brasileiros. Horizontes Antropológicos, Porto Alegre, v.13, n.28, 2007, p.87-116. Disponível em: http://www.scielo.br/pdf/ha/v13n28/a05v1328.pdf Acessado em: 10.04.2017.

BARTHES, R. Toward a psychosociology of contemporary food consumption. In: COUNIHAN, C.; VAN ESTERIK, P. (org). Food and culture: a reader. 3.ed. New York: Routledge, 2013. 
BEARDWORTH, A.; KEIL, T. Sociology on the menu. Padstow: TJ Press, 1997.

BONIN, A. M.; ROLIM, M. do C.. Hábitos alimentares: tradição e inovação. Boletim de Antropologia. Curitiba, 4(1), pp.75-90, jun.1991.

BOURDIEU, P. Gostos de classe e estilos de vida. IN:ORTIZ, Renato. Sociologia. São Paulo: Ática, 1983.

BOUTAUD, J. Compartilhar a mesa. IN: MONTANDON, Alan. (org). O livro da hospitalidade. São Paulo: SENAC, 2011, p.1.213-1.230.

CAMPI, M. Porta garrafas anula sinal de celular em mesa de bar. 9.ago.2013. Disponível em: http://exame.abril.com.br/tecnologia/porta-garrafa-anula-sinal-de-celular-em-mesa-de-bar/

Acessado em: 12.jul.2017.

CARNEIRO, H. Comida e sociedade: significados sociais na história da alimentação. Revista História: Questão \& Debates, Curitiba, n.42, 2005, p.71-80.

CARVALHO, L. G.; BASTOS, S.; GIMENES-MINASSE, M. H. Comensalidade na família nuclear paulistana - 1950-2000. Revista Rosa dos Ventos, v.1, n.9, 2017. Disponível em: http://www.ucs.br/etc/revistas/index.php/rosadosventos/article/view/4863 Acessado em: 10.abr.2017.

COSTA, L. Alimentação e comensalidade entre os Kanamari da Amazônia Ocidental. Mana, 13, (3), Rio de Janeiro, dez.2013. Disponível em: http://www.scielo.br/scielo.php?pid=S010493132013000300003\&script=sci_arttext\&tlng=es Acessado em: 10.05.2017.

CRUSHING TABLE. $O$ que é. Disponível em: http://www.crushingtable.com.br Acessado em: 12.abr.2017. Acessado em: 14.04.2016.

DANESI, G. Comparing commensality: festive eating occasions among French, German and Spanish young adults. Antropology of food, v.10, n.1, 2014. Disponível em: https://aof.revues.org/7708 Acessado em: 10.04.2017.

DE BOER, L.; REJOWSKI, M. Dimensões da hospitalidade em um restaurante comercial. Revista Turismo e Sociedade, 9 (1), 2016. Disponível em: https://revistas.ufpr.br/turismo/article/view/45020 Acessado em 08.abr.2017.

DEBORD, G. A sociedade do espetáculo. Rio de Janeiro: Contraponto, 1997.

DENCKER, A. M. Métodos e técnicas de pesquisa em turismo. São Paulo: Futura, 1999.

EATWITH. About us. Disponível em: https://www.eatwith.com/ Acessado em: 12.abr.2017. 
EXAME. Cerveja Polar cria 'Anulador de Celular'. 8.ago.2013. Disponível em: http://exame.abril.com.br/marketing/cerveja-polar-cria-anulador-de-celular/ Acessado em: 13.jul.2017.

FISCHLER, C. El (h)omnívoro: el gusto, la cocina y el cuerpo. Barcelona: Anagrama, 1995.

FISCHLER, C. A McDonaldização dos costumes. In: FLANDRIN, J.L.; MONTANARI, M. História da alimentação. São Paulo: Liberdade, 1998, pp. 841-862.

FOLHA DE SÃO PAULO. Aplicativo quer ajudar quem não gosta de sair par a jantar sozinho. Disponível em: http://classificados.folha.uol.com.br/negocios/2015/05/1632448-aplicativo-quer-ajudar-quemnao-gosta-de-sair-para-jantar-sozinho.shtml Acessado em: 12.abr.2017.

GASTAL, S.; MARTINS, C. Hospitalidade e Festa do Espírito Santo: contributos da caridade, misericórdia e comensalidade. Disponível em: https://www.revhosp.org/hospitalidade/article/view/766/803 Acessado em: 18.out.2018.

GIMENES-MINASSE, M. H. S. Cozinhando a tradição - festa, cultura, história e turismo no litoral paranaense. UFPR: Curitiba, 2013.

GRASSI, M.-C.. Hospitalidade - transpor a soleira. In: MONTANDON, Alain (Org.). O livro da hospitalidade. Acolhida do estrangeiro na história e nas culturas. São Paulo: Senac, 2011, p. 45-53.

GREVET, C.; TANG, A.; MYNATT, E. Eating alone, together: new forms of commensality. GROUP'12 Proceedings of the $17^{\text {th }}$ ACM International Conference on Supporting Group Work, ACM. New York, 2012, p.103-106. Disponível em: https://www.semanticscholar.org/paper/Eating-alone-together-new-forms-of-commensalityGrevet-Tang/1e75c0fbc6376fd199c80a777028dddaac56c6df Acessado em: 15.abr.2017.

HALL, J. Instagram has dramatically changed the nation's eating habits - and that's no bad thing. Telegraph Online, 2 de novembro de 2016. Disponível em http://www.telegraph.co.uk/men/the-filter/instagram-has-dramatically-changed-the-nationseating-habits---a1/ Acessado em: 25.06.2017.

HOSIE, R. How Instagram has transformed the restaurant industry for millennials. Independent Online, 11 de abril de 2017. Disponível em http://www.independent.co.uk/life-style/food-anddrink/millenials-restaurant-how-choose-instagram-social-media-where-eat-a7677786.html.

HERNANDES CONTRERAS, J.; GRACIA ARNAIZ, M. Alimentação, cultura e sociedade. Rio de Janeiro: Fiocruz, 2011.

IBGE. Cidades. São Paulo. 2014. Disponível em: http://cidades.ibge.gov.br/xtras/perfil.php?codmun=355030 Acessado em: 12.abr.2017. IFOOD. Sobre. Disponível em: https://ifood.delivery/br/sobre Acessado em: 14.jul.2017. 
LASHLEY, C.; MORRISON, A.; RANDALL, S. Uma refeição inesquecível! A hospitalidade como experiência emocional. In: SLOAN, D. (org). Gastronomia, restaurantes e comportamento do consumidor. São Paulo: Manole, 2005, p.191-214.

LÉVY, P. A inteligência coletiva: por uma antropologia do ciberespaço. São Paulo: Loyola, 2003.

LOBSTR. Lobstr - encontre alguém para almoçar. Disponível em: https://www.getlobstr.com/ Acessado em: 13.07.2017.

LOPES, A. F. L. O gênero do cuidado em si: as implicações da dieta alimentar na comensalidade de diabéticos. Cadernos Pagu, (36), jan-jun, 2011, p.345-374. Disponível em: http://www.scielo.br/pdf/cpa/n36/n36a13 Acessado em 12.05.2017.

MIRSA, S.; CHENG, L.; GENEVIE, J.; YUAN, M.. The Iphone effect: the quality of in-person social interactions in the presence of mobile devices. Enviroment and behavior, 1 (24), 2014. Disponível em: http://journals.sagepub.com/doi/abs/10.1177/0013916514539755 Acessado em: 15.abr.2017.

MENEZES, G.. "Tinder dos restaurantes” aposta em encontros durante o almoço. 01.jun.2017. Disponível em: http://vejasp.abril.com.br/cidades/aplicativo-lobstr/ Acessado em: 10.mai.2017.

MOSER, C.; SCHOENEBECK, S.; REINECKE, K. Technology at the table: attitudes about mobile phone at mealtimes. CHI'16 California, 07-12.may, 2016. Disponível em: http://yardi.people.si.umich.edu/pubs/Schoenebeck_PhoneMealtimes16.pdf $\quad$ Acessado em:16.abr.2017.

NAPKIN SOCIAL. Napkin - o seu guardanapo social de mensagens. Disponível em:

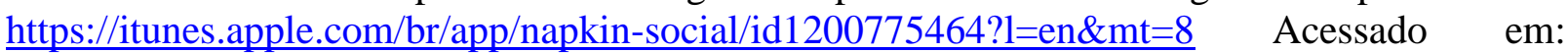
13.jul.2017.

NERI, G. Cansou de comer ou turistar sozinho? Esses apps podem te ajudar a sair da solidão. Revista Veja [on line]. 11. mai.2015. Disponível em: http://veja.abril.com.br/tecnologia/cansoude-comer-e-turistar-sozinho-esses-apps-podem-te-ajudar-a-sair-da-solidao/ Acessado em: 12.abr.2017.

POLLO, L. Sem 'pressão' por match, aplicativo marca refeições com desconhecidos. O Estado de São Paulo. Disponível em: http://emais.estadao.com.br/noticias/comportamento,sempressao-por-match-aplicativo-marca-refeicoes-com-desconhecidos, 10000084832 Acessado em: 12.abr.2017.

POULAIN, J. Sociologias da alimentação: os comedores e o espaço social.

Florianopolis:UFSC, 2013.

ROUSSEAU, S. Food and Social Media: You Are What You Tweet. Laham: AltaMira Press, 2012. 
SALLES, D. O EatWith conecta quem curte cozinhar a quem gosta de gastronomia. Revista Época [on line]. Disponível em: http://epoca.globo.com/regional/sp/morar/noticia/2013/09/bosite-eatwith-conecta-quem-curte-cozinharb-quem-gosta-de-gastronomia.html Acessado em $\underline{12.04 .2017}$.

SIMMEL, G. The sociology of the meal. FRISBY, D.; FEATHERSTONE, M. (eds.). Simmel on culture: selected writings. New York, NY : Sage, 1998.

SOBAL, J.; NELSON, M. Commensal eating patterns: a community study. Appetite, n.41, 2003, p.181-190. Disponível em: http://eng105i016ethnographies.web.unc.edu/files/2016/11/commensal-eating-patterns-acommunity-study.pdf Acessado em: 10.abr.2017.

SOARES, C.; CAMARGO, L. O. L. Produção científica sobre comensalidade no Brasil (19972011). Revista Rosa dos Ventos, 7 (2), 2015. Disponível em: http://www.ucs.br/etc/revistas/index.php/rosadosventos/article/view/3410 Acessado em: 09.abr.2017.

TRAPHAGAN; J.; BROWN, K. Fast food and intergenerational commensality in Japan. Ethnology, v., n.41, n.2, 2002, p.119-134.

TUOMAINEN, H. Eating alone or together? Commensality among Ghanaians in London. Anthropology of food, s10, 2014. Disponível em: https://aof.revues.org/7718 Acessado em 10.abr.2017.

VEJA. Bar cria copo offline para inibir o uso de celular durante o happy hour. 07.jun.2013. Disponível em: http://veja.abril.com.br/economia/bar-cria-copo-offline-para-inibir-uso-docelular-em-happy-hour/ Acessado em: 12.abr.2017.

WOORTMANN, K. A comida, a família e a construção de gênero. Brasília: UNB; 1985.

Artigo recebido em: 19/10/2018

Avaliado em: $16 / 11 / 2018$

Aprovado em: 14/12/2018 